\title{
ENNAKKOTIETOJA HERNEEN JA VIRNAN SÄILYVYYDESTÄ SEOSVILJOISSA SUOMESSA.
}

\author{
P. HänNINEN. \\ Maatalouskoelaitos, Kasvinviljelysosasto, Tikkurila.
}

Saapunut 31.1.1949.

Maassamme on julkaistu useita erillisiä koetuloksia palkokasviseosviljoista $(1,4,5,6,10,11)$. Niissä on yleensä todettu herneen osuuden olevan siemensadossa tuntuvasti pienemmän kuin käytetyssä kylvösiemenessä. Päinvastaisiakin tuloksia on saatu $(1,11)$. Virnalla ei toistaiseksi ole suoritettu riittävästi kokeita, joten sen suhteen ei varmaa ole voitu sanoa (10).

Seuraavassa tarkastellaan palkokasvien säilyvyyttä jo julkaistun aineiston ja tekijän v. 1947 aloittamien kenttäkokeiden tulosten perusteella. Lisäksi on tehty kenttähavaintoja eri osissa maata ja suoritettu erikoiskoe.

Herneen tai virnan säilyvyyttä seosviljoissa voidaan tarkastella usealta eri näkökannalta. Seuraavassa otetaan tarkastelun kohteeksi niiden prosenttinen osuus saaduissa siemensadoissa. Jos säilyvyys on hyvä, on sadossa palkokasveja prosenttisesti likimäärin yhtä paljon tai enemmänkin kuin vastaava kylvösiemen edellyttää. Päinvastainen tapaus merkitsee heikkoa säilyvyyttä.

Käsiteltävät koepaikat on esitetty kuvassa 1. Tulosten tarkastelussa on huomattava, että varsinkin herne on tunnetusti oikullinen viljelyskasvi. Virnaa on pidettävä huomattavasti varmempana (10). Siten on yksityisten koevuosien osalta todettavissa huomattavia vaihteluja. Seuraavassa on kuitenkin käytetty säilyvyyttä tarkasteltaessa yleensä monivuotisia keskiarvotuloksia. Mikäli koevuosia on ollut vain yksi, on siitä mainittu.

Etelä-Suomessa suoritettujen kokeiden mukaan (koepaikat Tammisto, Jokioinen, Tikkurila) herneen säilyvyys on ollut seosviljoissa heikko (4, 5, 10). Kokeiltujen hernelajikkeiden (Artturi, Sinikka, Koivisto, Martta, Torstai II) kesken on todettu eroja. Parhaimmin säilyväksi on esitetty Sinikka-hernettä $(5,7)$. Virnan säilyvyyttä on kokeiltu vain yhdessä koepaikassa, Tikkurilassa (10). Tulos on ollut selvästi edullisempi kuin Sinikka- ja Artturi-herneillä (10, pp. 118-119, 126-127, 130-131). Koejakson sääsuhteet ovat olleet kuitenkin VALLEn mukaan kovin edulliset virnalle ja hän mainitsee saaneensa huomattavan heikkojakin tuloksia virnakaurakokeissaan (10, p. 123). Etelä-Suomen p.o h jois os is s a ovat VIRRI 


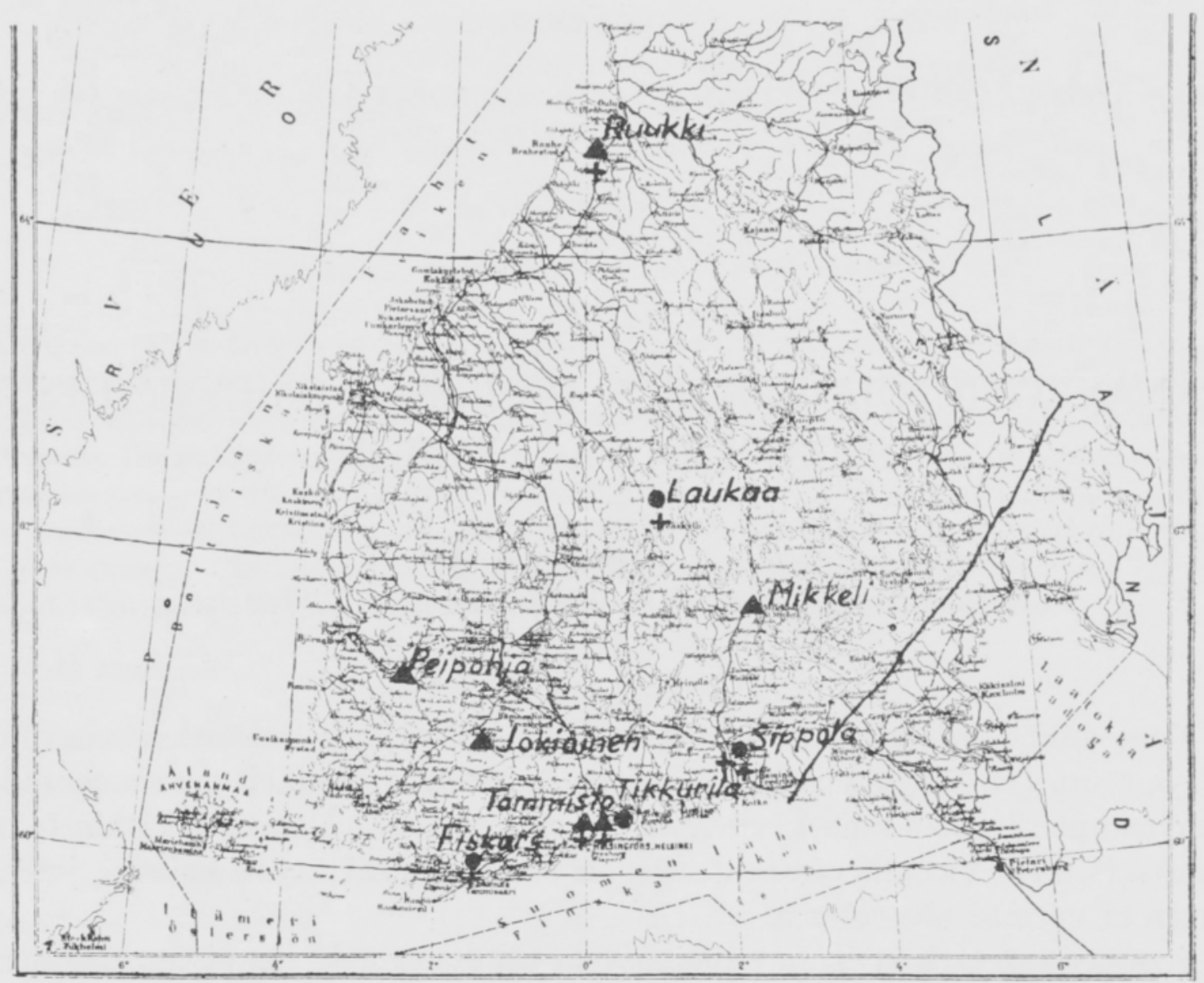

Kuva 1. Koe- ja havaintopaikat.

= julkaistuja tuloksia.

- = tekijän tuloksia. $\quad+=$ tekijän kenttähavaintoja.

Fig. 1. Experimenting and observation places. $\mathbf{\Delta}=$ results already published. $+=$ field observations of the author.

ja Koskinen suorittaneet hernekaurakokeita. Virrin (koepaikka Peipohja) tulokset (11) osoittavat Artturi-herneen säilyneen varsin hyvin. Runsaammin hernettä sisältäneissä koejäsenissä sen säilyvyys on ollut jopa erinomainen. Sitävastoin ovat Torstai ja Koivisto osoittautuneet h e i k o iksi. Koskisen aineisto (koepaikka Mikkeli) käsittelee vain yhden koevuoden tuloksia (6). Käytetty lajike oli Solo-herne. Tulos on ollut jossain määrin ristiriitainen. KOSKISEN pitkäaikainen edullinen kokemus lajikkeesta talousviljelyksillä viitannee hyvään säilyvyyteen.

K eski-Su o mesta ei ole julkaistu palkokasviseosviljoista koetuloksia. Poh jois-S u o m en osalta on käytettävissä AntTisen Ruukissa suorittamien hernekaurakokeiden tulokset (1). Hän on käyttänyt kokeissaan pääasiassa Express- ja Torstai II-herneitä, joiden säilyvyys on ollut kokeissa hyvä. Tulos poikkeaa erittäin selvästi Etelä-Suomesta saaduista kokemuksista. AntTinen on maininnutkin tästä esittämättä kuitenkaan syitä ilmiöön (1, p. 32). AnttiseN saamaa tulosta on pidettävä sitäkin merkittävämpänä, kun esim. Torstai II VIRR In edellä selostettujen kokeiden ja PEsolan (7) mukaan säilyy kovin heikosti seosviljoissa. 
Taulukko 1. Sinikka-herneen ja virnan säilyvyys seosviljoissa kenttäkokeissa v. 1947 eri koepaikoissa.

Table 1. The survival of Sinikka pea and vetch in mixed crops in various places (1947).

\begin{tabular}{|c|c|c|c|c|c|c|c|}
\hline \multirow{3}{*}{\multicolumn{2}{|c|}{$\begin{array}{l}\text { Koepaikka } \\
\text { Place }\end{array}$}} & \multicolumn{6}{|c|}{$\begin{array}{l}\text { Herneen tai virnan osuus sadossa } \% \text {, kun siemenessä on ollut } \\
\text { The percentage of pea or vetch in the grain yield when in the seed }\end{array}$} \\
\hline & & \multicolumn{3}{|c|}{$\begin{array}{l}\text { hernettä \% } \\
\text { pea } \%\end{array}$} & \multicolumn{3}{|c|}{$\begin{array}{r}\text { virnaa } \% \\
\text { vetch } \%\end{array}$} \\
\hline & & 12,5 & 25 & 50 & 12,5 & 25 & 50 \\
\hline Tikkurila & $\ldots \ldots$ & 5,0 & 10,5 & 27,9 & 4,6 & 13,0 & 35,5 \\
\hline Fiskars & $\ldots \ldots \ldots$ & 8,3 & 17,6 & 36,9 & 10,7 & 21,3 & 42,0 \\
\hline Sippola & $\ldots \ldots \ldots$ & 5,5 & 8,1 & 23,0 & 6,1 & 15,6 & 35,6 \\
\hline Laukaa & $\ldots \ldots \ldots$ & 11,0 & 25,3 & 51,5 & 9,3 & 21,0 & 49,8 \\
\hline
\end{tabular}

Taulukosșa 1 on esitetty tekijän kenttäkokeissa saamia tuloksia vuodelta 1947.

E t elä-S u o me a edustavat Tikkurila, Fiskars ja Sippola. Herneen (Sinikka) säilyvyys vahvistaa jo aiemmin Etelä-Suomesta saatua kuvaa. Virnan säilyvyys on ollut Tikkurilassa ja Sippolassa myös heikko. Kuitenkin näyttäisi virna säilyneen molemmissa paikoissa selvästi paremmin kuin Sinikka-herne. Fiskarsissa virna on säilynyt varsin hyvin. Kun kasvukausi 1947 oli erinomaisen kuiva, ovat tulokset sitäkin edullisempia virnalle, jota yleensä pidetään kuivanarkana. VALLEn kokeissa (10) tulokset viittasivat virnan säilyvän hernettä paremmin. Saatu samansuuntainen tulos vahvistaa tätä käsitystä. V. 1948 saadut säilyvyystulokset ovat osaksi olleet vieläkin edullisempia virnalle. N äyt t ää i $1 \mathrm{~m}$ e i s e $1 \mathrm{t}$ ä, e t t ä virna säilyy Etelä-Suomen oloissa seosviljoissa paremmin kuin Artturi-ja Sinikka-herneet.

Keski-Suomea edustavat taulukossa Laukaasta saadut koetulokset. Huomiota herättää, että siellä on Sinikka-herne säilynyt hyvin. Koevuosia on toistaiseksi kuitenkin vain yksi. - Virnakin on säilynyt Keski-Suomen oloissa yllättävän hyvin. Sinikka-herneen kanssa se silti ei ole voinut täysin kilpailla.

Kokeiden tarkastelu osoittaa, että tuloksissa on herneen osalta huomattavia vaihteluja. Kun herne on tunnetusti oikullinen viljelysk a s vi, on vaikeata sanoa, mikä tai mitkä kasvutekijät kulloinkin ovat vaikuttaneet hyvään tai huonoon säilyvyyteen. Virnan säilyvyys näyttää tasaisemmalta. On luonnollista, että maan yleisellä kasvukunnolla, kasvinravintoaineilla ja maalajilla täytyy olla tärkeä merkitys herneen ja virnan säilyvyyteen seosviljoissa. Edelleen on otettava huomioon kasvukauden sääsuhteet, joista varsinkin sademäärää ja etenkin sen jakautumista kasvukauden eri osien kesken on pidettävä tärkeänä $(3,10)$. Mainitut tekijät eivät silti y k s i n kyenne selittämään saatuja tuloksia. Kun tarkastellaan herneestä koko maassa saatua kuvaa, voidaan selvästi todeta säilyvyyden parantuneen etelästä pohjoiseen mentäessä. Siten on Torstai II Etelä-Suomessa menestynyt heikosti $(7,11)$, Pohjois-Suomessa sitävastoin hyvin (1). Sinikka on etelässä antanut heikon tuloksen (10). Keski-Suomessa tulos on ollut hyvä. Artturi on maan eteläisimmässä osassa (Tammisto) säilynyt heikosti (4), kun taas pohjoisempana (Peipohja) selvästi paremmin (11). Näihin t o i s t u v i i n 
ilmiöihin ei voine olla muuta selitystä kuin päivän piteneminen pohjoiseen mentäessä. Tässä mielessä on kesällä 1948 suoritettu eri puolilla maata kenttähavaintoja seosviljakasvustoissa (kuva 1). Nämä osoittivat herneen kasvavan pohjoisempana (= pitemmän päivän alueella) tuntuvasti kookkaammaksi kuin etelässä. Siten oli Pohjois-Suomessa (Ruukki) vaikeata tuntea Etelä-Suomessa matalakasvuisena pidettyä (10) Torstai II-hernettä. Edelleen on jo maan eteläosissa kookkaaksi tunnettu Sinikka-herne (7) osoittautunut sekä 1947 että 1948 huomattavasti reheväkasvuisemmaksi pohjoisempana (Laukaa). Myös kauran kasvu näyttäisi rehevöityvän pohjoiseen päin mentäessä, ei kuitenkaan yhtä voimakkaasti kuin herneiden. Havaittu ilmiö voisi osaltaan selittää myös saadut herneen säilyvyystulokset.

Kysymystä on lisäksi tutkittu v. 1948 järjestämällä seosviljoilla erikoiskoe. Kokeessa käytettiin sekä herne- että virnakauraa. Molemmissa oli palkokasvien osuus kylvösiemenessä 25 paino-\%. Kokeen suorituksessa on seurattu POHJAKALLion ja SALOSEN (8) käyttämää pimennyskokeiden tekniikkaa. Kun Etelä-Suomen päivä näytti liian lyhyeltä, koe sijoitettiin Keski-Suomeen, Laukaaseen. Käytetty Torstai II-herne kasvoi kauraan verrattuna heikonlaisesti sekä lyhyttä päivää (= 10 tuntia) että normaalipäivänpituutta edustavilla koeruuduilla. Näytti kuitenkin siltä, että lyhyen päivän ruuduilla kaura olisi pahemmin tukahduttanut herneen kasvun kuin normaalissa valaistuksessa. Virna kasvoi kauran kanssa likimäärin tasaveroisesti sekä pitkän päivän että lyhyen päivän oloissa. Havainnot tukenevat edellä käsiteltyjä koetuloksia ja esitettyä päivänpituuden vaikutusta. PohjakAllio ja SALONEn ovat julkaisseet tuloksia pimennyskokeista hernekauroilla (9). Niiden mukaan on lyhyt päivä (=10 tuntia) yleensä pienentänyt kauran varsisatoa enemmän kuin herneen. Kokeet on kuitenkin suoritettu maan eteläisimmässä osassa (koepaikka Helsinki).

Ruotsissa on julkaistu varsin laaja seosviljakokeiden yhdistelmä (2). Myös siellä on todettu useassa tapauksessa herneen säilyvyyden parantuneen etelästä pohjoiseen päin mentäessä (2, pp. 86-94, 102). Syitä tähän ei ole kuitenkaan esitetty.

Kun ruotsalaisissa kokeissa herne on säilynyt yleensä hyvin (2), tosin säilyvyydeltään heikkojakin lajikkeita on todettu, ja tulokset on saatu suurelta osalta huomattavasti eteläisemmilta alueilta kuin Suomi, tuntuisi olevan syytä kokeilla maamme eteläosissa siellä parhaiten säilyneillä lajikkeilla. Tällaisia lajikkeita ovat olleet mm. Solo ja Hero.

\section{Yhteenveto.}

Tutkimuksessa on käsitelty Suomessa suoritettuihin koetuloksiin nojautuen herneen ja virnan säilyvyyttä seosviljoissa lähinnä siemensatojen perusteella. Tällöin on todettu:

1. Kokeissa olleet hernelajikkeet, Artturi, Sinikka, Koivisto, Martta ja Torstai II, ovat säilyneet maan eteläisimmissä osissa heikosti. Pohjoiseen päin mentäessä lajikkeen säilyvyys näyttää paranevan. 
2. Virna on osoittautunut eräitä hyvinä pidettyjä hernelajikkeita selvästi paremmin säilyväksi maan eteläosissa.

3. Kohdassa 1 mainitun toteamuksen syyksi on esitetty erilainen päivänpituus eri osissa maata. Tätä näyttäisivät tukevan kenttähavainnot ja vuonna 1948 suoritettu erikoiskoe, samoin eräät ruotsalaiset koetulokset.

\section{KIRJALLISUUTTA.}

(1) Antrinen, O. 1948. Hernekauran viljelysmahdollisuuksista Pohjois-Pohjanmaalla. Koetoiminta ja käytäntö, 5, p. $31-32$.

(2) Eliasson, Sture (ref.) \& Jacobson, G. 1946. Sortförsök med ärter och baljväxtblandsäd. Lantbrukshögskolan jordbruksförsöksanstalten, Medd. 17, p. 108.

(3) Ericsson, Gust. \& Genchel, M. 1947. Försök med ärter och ärtblandsäd vid statens försöksgård Offer åren 1935-1946. Lantbrukshögskolan jordbruksförsöksanstalten, Medd. 21, p. 67 .

(4) Huttunen, E. 1939. Kokemuksia hernekauran viljelemisestä tuleentuneeksi. Pellervo 1939, p. $226-228$.

(5) Kankare, A. 1948. Koetuloksia herneen ja kauran seosviljelyksestä. Käytännön maatalous 1948 , p. $9-10$.

(6) Koskinen, Y. K. 1948. Eräitä koetuloksia ja kokemuksia rehupalkokasvien viljelystä EteläSavon koeasemalla. Koetoiminta ja käytäntö, 5, p. 40.

(7) Pesola, V. A. 1939. Sinikka uusi vihreä talousherne. Valt. maatal. koet. tied., 158, p. 15.

(8) Pohjakallio, O. \& Salonen, A. 1947. Der Einfluss der Tageslänge auf Entwicklung und Energiehaushalt einiger Kulturpflanzen. Acta Agralia Fennica, 67, 1, p. 51.

(9) —- 1948. Über den Einfluss von Erbse auf die Trockensubstanzerzeugung von Hafer in Erbse-Hafer-Mischbestand. Maataloustiet. Aikak., 20, p. 143-156.

(10) Valle, O. 1946. Palkokasvien merkitys rehuviljan tuotannossa. Maatalous ja koetoiminta, I, p. $115-134$.

(11) VirRi, T. J. 1939. Herne-kauran viljelystä. Valt. maatal. koet. tied., 164, p. 11.

\section{SUMMARY.}

PRELIMINARY REPORTS ON THE SURVIVAL OF PEAS AND VETCHES IN MIXED CROPS IN FINLAND.

By

P. Hänninen.

Central Agricultural Experiment Station, Department of Agronomy, Tikkurila.

In the investigation the author has collected results, already published, concerning the survival of peas and vetches in mixed crops in Finland, and supplemented them with results of his own field experiments (Table 1). In addition to these, observations in different parts of the country have been made (Fig. 1).

Results have shown that the pea varieties used have not survived in the southern part of Finland as well as in the middle and northern part of the country. In southern Finland vetch has given better results than peas. Better survival of pea varieties (Artturi, Sinikka and Thursday II) in more northern places has been explained as being due to the difference in the length of the day. Some Swedish results seem to corroborate this opinion (2). 